\title{
Theoretical Study of the Kinetics of the Pyrolytic Elimination Reaction of Ethyl Chloride
}

\author{
ISAIAH AJIBADE ADEJORO and EMMANUEL EKEH \\ Department of Chemistry, \\ University of Ibadan, Ibadan, Nigeria. \\ ia.adejoro@mail.ui.edu.ng
}

Received 5 October 2007; Revised 20 December 2007; Accepted 20 February 2008

\begin{abstract}
The products of the gas-phase elimination of ethyl chloride are hydrogen chloride and ethane. Using AM1, MNDO and PM3 Hamiltonians of quantum mechanical computer code called MOPAC, a procedure for the kinetics and computation of the Arrhenius parameters for the pyrolytic elimination reaction of ethyl chloride was devised in order to evaluate the predictive ability of the three Hamiltonians used. The first-order rate coefficient for the three Hamiltonians are $1.15 \times 10^{-8} \mathrm{~s}^{-1}, 4.55 \times 10^{-15} \mathrm{~s}^{-1}$ and $5.36 \times 10^{-4} \mathrm{~s}^{-1}$ for AM1, MNDO and PM3 respectively. The results obtained showed that the rate constant for the computed Arrhenius parameters compare well with the experimental values in the literature, thus showing that the computational procedure adequately simulates experimental results; also the semi-empirical AMI calculation has the best predictive ability with experiment followed by PM3 while MNDO has the least.
\end{abstract}

Keywords: Kinetics, Unimolecular elimination, Semi-empirical calculation, MOPAC.

\section{Introduction}

The presence of $\mathrm{C}_{\beta}-\mathrm{H}$ on the alkyl side of an organic halide, such as chlorides, leads to a gas-phase elimination through a four-centered cyclic transition state type of mechanism. A large number of gas-phase unimolecular reaction, which have been studied, appeared to take place by way of 4 -centre and 6-centre cyclic activated complexes ${ }^{1}$. The vast majority of the four-centre reactions are hydrogen halide eliminations from the alkyl halides to produce olefins. The reactions involve dehydrogenations, which go through four-centre transition states. The aim of this study is to devise a procedure for the theoretical study of the pyrolysis of ethyl chloride using semi-empirical approach in order to estimate how it can successfully predict the experimental results. The method is an adaptation of the one that was reported by Adejoro and Bamkole ${ }^{2}$ for alkyl acetates. 


\section{Computational method and model}

The kinetics for the gas-phase elimination reaction of $\mathrm{C}_{2} \mathrm{H}_{5} \mathrm{Cl}$ into $\mathrm{HCl}$ and $\mathrm{C}_{2} \mathrm{H}_{4}$ suggest a concerted mechanism. Theoretical calculations using the semi-empirical AM1, MNDO and PM3 methods were performed using MOPAC ${ }^{3}$.

The geometry of the ethyl chloride is defined in scheme 1 below<smiles>CC(C)(C)Cl</smiles>

\section{Scheme 1}

$\mathrm{H}_{7}$ is the $\beta$-hydrogen to be eliminated. The usual rules of geometry definition prescribed in MOPAC brochure were applied. Reaction path study was performed for the substrate using $\mathrm{H}_{7}-\mathrm{Cl}_{3}$ as reaction coordinate. By decreasing this bond length systematically in many small steps to the bond length in the product (about $1.29 \mathrm{~A}^{\circ}$ ), an approximate product structure was obtained and optimized.

Other aspects of the procedure such as saddle calculation, etcetera, were carried out as previously described by Adejoro and Bamkole ${ }^{2}$. The apparent enthalpy of activation was obtained for ethyl chloride through FORCE calculation on both the ground state, gs and transition state, ts, geometries by subtracting the enthalpy of the reactant at $623 \mathrm{~K}$ from the enthalpy of transition state at $623 \mathrm{~K}$. The correction computed is subtracted from the apparent enthalpy of activation.

According to the Transition State Theory (TST), for a unimolecular reaction

$$
\mathrm{Ea}=\Delta \mathrm{H}^{*}+\mathrm{RT}
$$

where $\Delta \mathrm{H}^{*}$ is the corrected enthalpy of activation, at $623 \mathrm{~K}$.

The apparent entropy $\Delta \mathrm{S}^{*}$ was obtained form the FORCE calculation by subtracting the entropy of the substrate at $623 \mathrm{~K}$ from the entropy of the transition state also at $623 \mathrm{~K}$. No consideration was given to the effect of internal rotation because chlorine is a single-atom substituent.

This was obtained by making corrections, $(\mathrm{R} \ln \sigma)$ for symmetry, where $\sigma$ is the number of equivalent $\beta$-hydrogen atoms available for elimination. It is otherwise known as the reaction path degeneracy. This is added and not subtracted as it can only enhance reaction.

$\Delta \mathrm{S}^{*}$ value was used to calculate Arrhenius pre-exponential factor using the relation,

$$
\mathrm{A}=\left\{\mathrm{e}^{\mathrm{m}} \mathrm{k}^{\prime} \mathrm{T} / \mathrm{h} \exp \left(\Delta \mathrm{S}^{*} / \mathrm{R}\right)\right\}
$$

where $\mathrm{m}$ is the molecularity of the reaction.

The first-order rate coefficient $\mathrm{k}(\mathrm{T})$ was calculated using $\mathrm{TST}^{4}$, and assuming that the transmission coefficient is equal to unity as expressed in the following equation:

$$
\mathrm{k}(\mathrm{T})=\mathrm{k}^{\prime} \mathrm{T} / \mathrm{h} \exp \left(-\Delta \mathrm{G}^{*} / \mathrm{RT}\right)
$$

where $\Delta \mathrm{G}^{*}$ is the Gibbs free energy change between the reactant and the transition state and $\mathrm{k}^{\prime}$ and $\mathrm{h}$ are the Boltzmann and Planck constants, respectively.

$\Delta \mathrm{G}^{*}$ was calculated using the following relation:

$$
\Delta \mathrm{G}^{*}=\Delta \mathrm{H}^{*}-\mathrm{T} \Delta \mathrm{S}^{*}
$$




\section{Results and Discussion}

Using the three Hamiltonians, the geometries of the reactant $\mathbf{1}$ and products $\mathbf{2}$ and $\mathbf{3}$ are predicted as shown below:<smiles>CCl</smiles>

1<smiles>CC(C)(C)Cl</smiles>

$\mathrm{H}_{5}$

Scheme 2

This study suggests that the gas-phase elimination reaction of ethyl chloride to give $\mathrm{HCl}$ and $\mathrm{C}_{2} \mathrm{H}_{4}$ occurs by a concerted non-synchronous mechanism. The transition state found is late in the reaction coordinate in relation to the breaking of $\mathrm{C}_{2}-\mathrm{Cl}_{3}$ and $\mathrm{C}_{1}-\mathrm{H}_{7}$ bonds and the formation of the $\mathrm{H}_{7}-\mathrm{Cl}_{3}$ bond. The transition state geometry is shown in scheme 3 below.

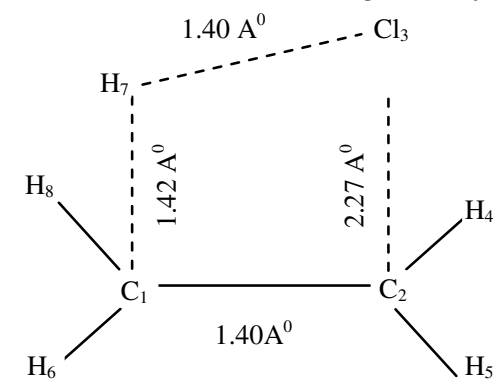

Scheme 3. The transition state geometry for the reaction.

The transition state for the reaction is a four-membered ring structure showing a very large $\mathrm{C}_{1}-\mathrm{H}_{7}$ distance as well as a large $\mathrm{C}_{2}-\mathrm{Cl}_{3}$ distance. Also chlorine is closer to $\mathrm{H}_{7}$ in the transition state. The geometric parameters shown in Table 1 indicate a product-like transition state.

Table 1. The geometric parameters.

\begin{tabular}{llll}
\hline Bond Length & AM1 & MNDO & PM3 \\
\hline $\mathrm{C}_{1}-\mathrm{C}_{2}$ (GS) & 1.50 & 1.52 & 1.51 \\
$\mathrm{C}_{1}-\mathrm{C}_{2}$ (TS) & 2.27 & 2.45 & 2.27 \\
$\mathrm{C}_{2}-\mathrm{Cl}_{3}$ (GS) & 1.75 & 1.81 & 1.78 \\
$\mathrm{C}_{2}-\mathrm{Cl}_{3}$ (TS) & 2.27 & 2.45 & 2.27 \\
$\mathrm{H}_{7}-\mathrm{Cl}_{3}$ (GS) & 3.39 & 3.00 & 3.42 \\
$\mathrm{H}_{7}-\mathrm{Cl}_{3}$ (TS) & 1.63 & 1.67 & 1.59 \\
$\mathrm{H}_{7}-\mathrm{C}_{1}$ (GS) & 1.12 & 1.11 & 1.10 \\
$\mathrm{H}_{7}-\mathrm{C}_{1}$ (TS) & 1.42 & 1.34 & 1.38 \\
$\mathrm{H}_{6}-\mathrm{C}_{1}$ (GS) & 1.12 & 1.11 & 1.10 \\
$\mathrm{H}_{6}-\mathrm{C}_{1}$ (TS) & 1.10 & 1.10 & 1.09 \\
$\mathrm{H}_{8}-\mathrm{C}_{1}$ (GS) & 1.12 & 1.11 & 1.10 \\
$\mathrm{H}_{8}-\mathrm{C}_{1}$ (TS) & 1.10 & 1.10 & 1.09 \\
$\mathrm{H}_{4}-\mathrm{C}_{2}$ (GS) & 1.10 & 1.11 & 1.10 \\
$\mathrm{H}_{4}-\mathrm{C}_{2}$ (TS) & 1.10 & 1.09 & 1.09 \\
$\mathrm{H}_{5}-\mathrm{C}_{2}$ (GS) & 1.12 & 1.11 & 1.10 \\
$\mathrm{H}_{5}-\mathrm{C}_{2}$ (TS) & 1.10 & 1.09 & 1.09 \\
\hline $\mathrm{Ground}^{2}$ &
\end{tabular}

Ground state $(G S)$ and Transition state $(T S)$ Atom Distances $\left(A^{\circ}\right)$ 
Calculated activation parameters from AM1 method are in reasonable agreement with the experimental values (Table 2).

Table 2.Comparative theoretical and expected activation parameter at $623 \mathrm{~K}$.

\begin{tabular}{llllcccc}
\hline \multicolumn{1}{c}{ Method } & \multicolumn{1}{c}{$\begin{array}{c}\mathrm{E}_{\mathrm{a}} \\
\mathrm{kJmol}^{-1}\end{array}$} & $\begin{array}{c}\Delta \mathrm{H}^{*} \\
\mathrm{kJmol}^{-1}\end{array}$ & $\begin{array}{c}\Delta \mathrm{S}^{*} \\
\mathrm{Jmol}^{-1}\end{array}$ & $\begin{array}{c}\Delta \mathrm{G}^{*} \\
\mathrm{kJmol}^{-1}\end{array}$ & $\begin{array}{c}\log \mathrm{A} \\
\mathrm{s}^{-1}\end{array}$ & $\begin{array}{c}\mathrm{k}^{1} \\
\mathrm{~s}^{-1}\end{array}$ & Ref. \\
\hline AMI & 255.90 & 250.66 & -0.690 & 251.09 & 13.51 & $1.15 \times 10^{-8}$ & \\
MNDO & 326.31 & 325.07 & 3.307 & 332.01 & 13.15 & $4.55 \times 10^{-15}$ & \\
PM3 & 200.2 & 195.01 & -0.742 & 195.47 & 13.51 & $5.36 \times 10^{-4}$ & \\
Experimental & 236.23 & & & & 13.16 & $2.25 \times 10^{-7}$ & 6 \\
& 248.95 & & & & 14.20 & $2.11 \times 10^{-7}$ & 7 \\
& 254.39 & & & & 14.60 & $1.89 \times 10^{-7}$ & 8 \\
Calculated & 236.4 & & & & 13.3 & $3.05 \times 10^{-7}$ & 1 \\
\hline
\end{tabular}

It is encouraging that this transition state satisfies the four criteria prescribed by Kormonicki and McIver ${ }^{5}$ The mechanism involves a cyclic transition state in which a $\beta-\mathrm{H}$ atom attacking the chloride atom is part of a four-membered cyclic transition state. This is corroborated by negative entropy of activation ${ }^{9}$

In the transition state, $\mathrm{C}_{2}-\mathrm{Cl}_{3}$ is stretched, whereas the $\mathrm{C}_{1}-\mathrm{H}_{7}$ bond is now a long bond and virtually broken while the $\mathrm{Cl}_{3}-\mathrm{H}_{7}$ bond is almost fully formed showing that the gasphase elimination reaction of $\mathrm{C}_{2} \mathrm{H}_{5} \mathrm{Cl}$ to give $\mathrm{C}_{2} \mathrm{H}_{4}$ and $\mathrm{HCl}$ occurs by a concerted nonsynchronous mechanism.

The transition state found is late in the reaction coordinate in the sense of the breaking of $\mathrm{Cl}_{3}-\mathrm{C}_{2}$ and $\mathrm{C}_{1}-\mathrm{H}_{7}$ bonds and the formation of $\mathrm{H}_{7}-\mathrm{Cl}_{3}$ bond. Calculated activation parameters are shown in Table 2 and they are in reasonable agreement with experimental value. First order rate coefficient is within an order of magnitude with both the experimental and calculated values.

Result from theoretical (semi-empirical method) approach shows that the reaction proceeds in a concerted mechanism, the TS being product-like or late with respect to reaction progress. The activation parameters are satisfactory and first-order rate coefficient from AM1 Table 2 is within an order of magnitude with both the experimental and calculated values. The semi-empirical AMI calculation has the best predictive ability with experiment followed by PM3 while MNDO has the least.

\section{References}

1 O'Neal H E and Benson S W, J Phys Chem., 1967, 71(9), 2903-2921.

2 Adejoro I A and Bamkole T O, J Appl Sci., 2005, 5(9), 1559-1563.

3 Stewart J J P, MOPAC Manual $6^{\text {th }}$ Ed., (QCMP 137), Indiana University, Bloomington, Indiana 47405, U.S.A. 1990, 26.

4 Benson S W, The Foundations of Chemical Kinetics: Mc-Graw-Hill, New York, 1960.

$5 \quad$ McIver J W and Kormonicki A, J Am Chem Soc , 1972, 94, 2625.

6 Tsang W, J Chem Phys.,1964, 41(8), 2487-2494.

7 Barton D H R and Howlett K E, J Chem Soc., 1949, 165.

8 Howlett K E, J Chem Soc., 1952, 3695.

9 Hurd C D and Blunck F H, J Am Chem Soc., 1938, 60(10), 2419-2425.

10 Cordova T, Rotinov A and Chuchani G, J Phys Org Chem., 2004, 17, 148-151. 


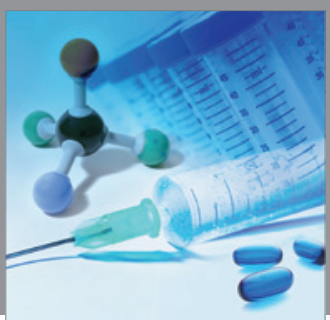

International Journal of

Medicinal Chemistry

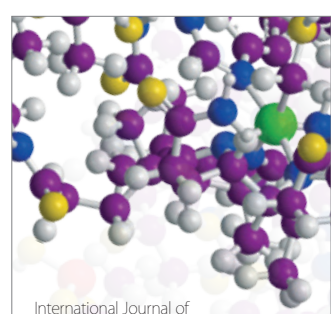

Carbohydrate Chemistry

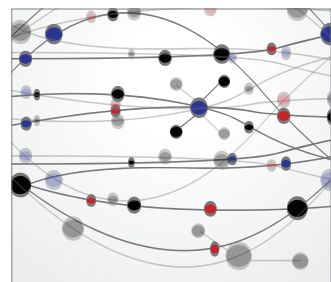

The Scientific World Journal
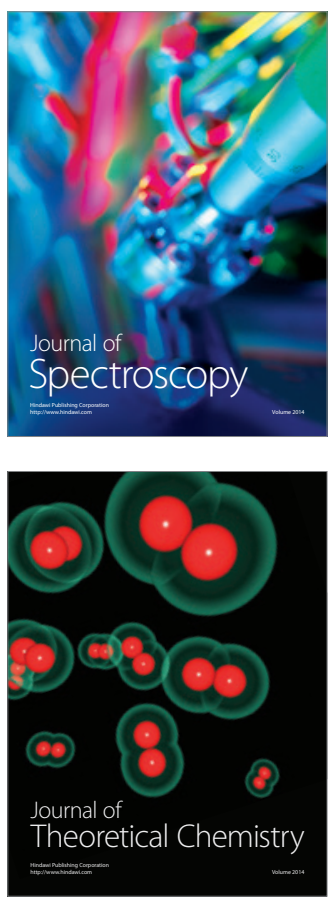
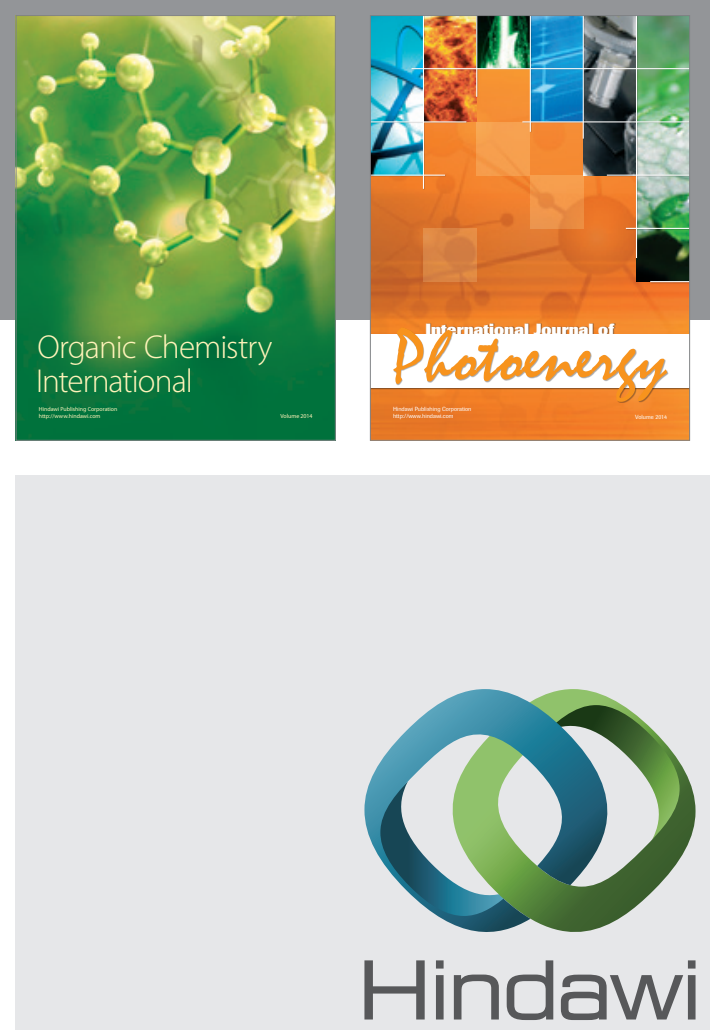

Submit your manuscripts at

http://www.hindawi.com
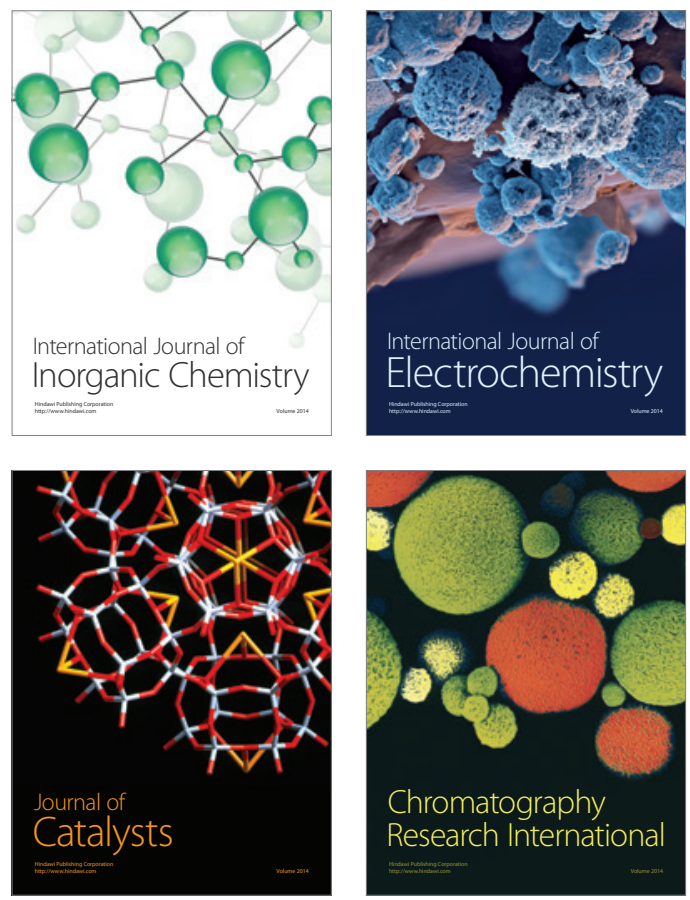
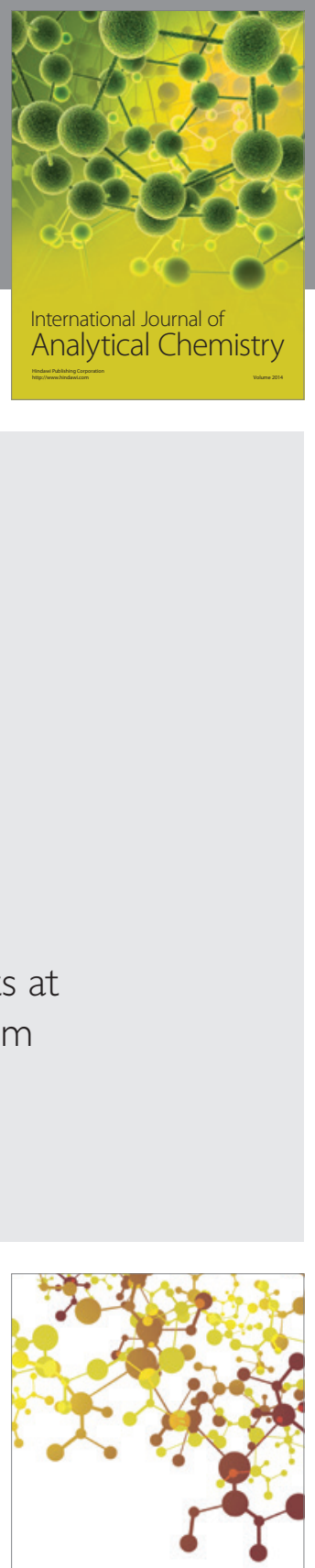

Journal of

Applied Chemistry
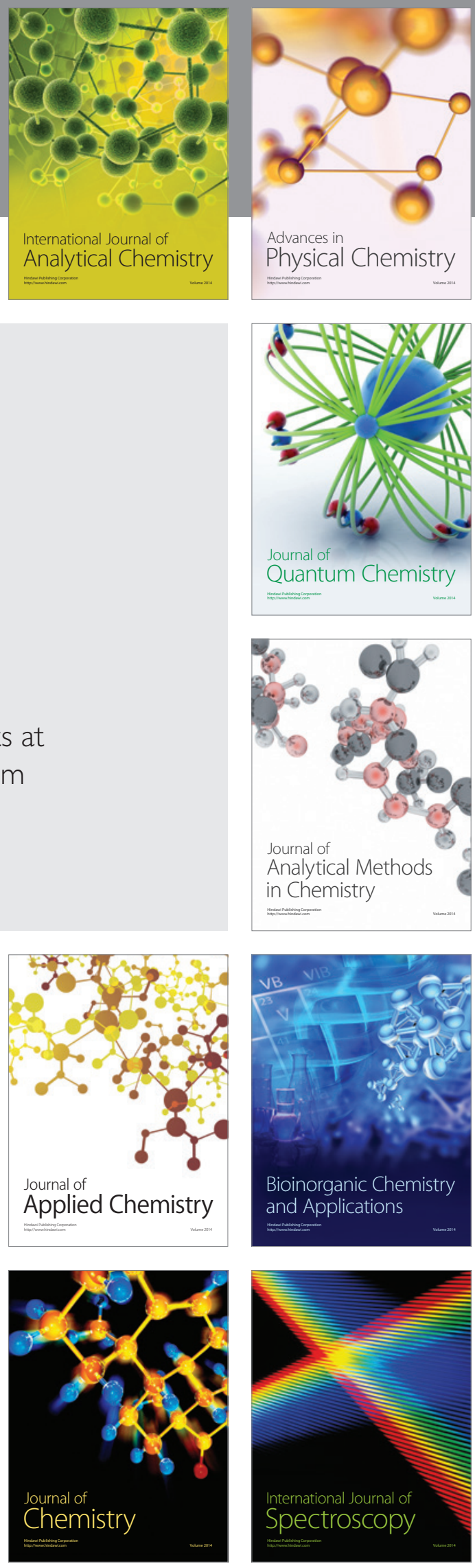